Western North American Naturalist 68(1), (C) 2008, pp. 113-118

\title{
OBSERVATIONS ON BODY MASS OF PRAIRIE DOGS IN URBAN HABITAT
}

\author{
Seth B. Magle1,2
}

\begin{abstract}
The black-tailed prairie dog is an important component of prairie and steppe ecosystems. Currently many prairie dog colonies are fragmented by, or adjacent to, urban development, but little is known about what effects urbanization may have on these animals. I compare body weights and sex ratios of prairie dogs in isolated urban habitat in Denver, Colorado, to published data for black-tailed prairie dogs at the same time of year. Prairie dogs in this study had summer weights similar to those reported in the literature, although males apparently gained weight earlier in the year, and observed sex ratios were not significantly different from 1:1. Although prairie dogs in urban areas face numerous threats, my study provides no evidence that urban forage is limited enough to result in decreased body mass or skewed sex ratios of urban prairie dogs.
\end{abstract}

Key words: prairie dogs, urban habitat, body mass, demography, sex ratio, Colorado.

The black-tailed prairie dog (Cynomys ludovicianus) is an important part of the shortgrass prairie and steppe ecosystems (Miller et al. 1990, 1994, 2000, Kotliar et al. 1999, Kotliar 2000, Soulé et al. 2003, 2005, but see Stapp 1998, Vermeire et al. 2004). However, agricultural and urban development, systematic extermination programs by humans, and sylvatic plague (Yersinia pestis) have reduced prairie dog distribution to $\leq 5 \%$ of the former geographic range (Miller et al. 1990, 1994, 2000, Kotliar et al. 1999). Many of the remaining prairie dog colonies are fragmented and isolated by urbanization and other human developments (Lomolino and Smith 2001, Magle 2003). Isolated urban habitat is associated with a number of risks to wildlife species in that habitat, including animal-vehicle collisions (Forman et al. 2003), human development (Magle 2007), increased abundance of introduced species (Soulé et al. 1992), and altered flow pathways and biogeochemical regimes (Kaye et al. 2006). When habitat is sufficiently fragmented to prevent or reduce dispersal between populations, extinction can result through inbreeding or stochastic demographic and environmental events (Hanski 1998, Crooks and Sanjayan 2006).

Prairie dogs that inhabit urban environments display modified behavioral patterns (Adams et al. 1987, Dawson 1991, Magle et al. 2005) and may not increase local species diversity (Lomolino and Smith 2003). In addition, prairie dogs in urban colonies bounded by a hostile human matrix have limited dispersal opportunities (the "fence" effect; Krebs et al. 1969, Johnson and Collinge 2004, Magle and Crooks in preparation) and attain population densities up to 5 times higher than their counterparts in unfragmented landscapes (Johnson and Collinge 2004, Magle et al. 2007). These urban prairie dogs may have limited available forage, leading to decreased body mass and increased risk of local extinction (Dawson 1991). However, basic data on the body mass of prairie dogs in urban areas is limited (but see Dawson 1991), and research in this area is needed (Johnson and Collinge 2004). In this study I provide information on body mass, sex ratios, and sexual dimorphism for prairie dogs in urban habitat.

As part of a larger study, I identified a series of isolated habitat fragments in Denver, Colorado, and its south suburbs along a gradient of urbanization (Magle 2003). In 2002, a census of this study area (about $374 \mathrm{~km}^{2}$ ) revealed 397 habitat fragments, 54 of which were colonized by prairie dogs. These habitat fragments were bounded on all sides by roads and human development. To obtain information on body mass and sex ratios of urban prairie dogs, I randomly selected 7 prairie dog colonies (average area $2.92 \mathrm{ha}$, range $0.25-15.02 \mathrm{ha}$ ) within this study system from the subset of sites where I was permitted to trap prairie dogs. Sites were similar in that all

${ }^{1}$ Department of Fish, Wildlife, and Conservation Biology, Graduate Degree Program in Ecology, Colorado State University, Fort Collins, CO $80523-1474$.

${ }^{2}$ Present address: Nelson Institute for Environmental Studies, University of Wisconsin-Madison, Madison, WI 53706. E-mail: sbmagle@wisc.edu 
Table 1. Summary data for prairie dogs on colonies in Denver, Colorado.

\begin{tabular}{|c|c|c|c|c|c|c|c|}
\hline Colony & Year & Sex & $n$ & Mean weight (g) & Range & $s_{\bar{x}}$ & Dates trapped \\
\hline \multirow[t]{2}{*}{ J15-10 } & 2005 & Male & 40 & 846.3 & $610-1200$ & 24.1 & 12 May-7 Jun \\
\hline & & Female & 52 & 735.6 & $540-1190$ & 18.5 & \\
\hline \multirow[t]{2}{*}{ K15-36 } & 2004 & Male & 8 & 1025.3 & $810-1300$ & 79.6 & 4 Aug-9 Aug \\
\hline & & Female & 4 & 1075.1 & $820-1490$ & 263.0 & \\
\hline \multirow[t]{2}{*}{ K15-36 } & 2005 & Male & 3 & 783.3 & $550-1210$ & 208.8 & 8 Jul-11 Jul \\
\hline & & Female & 3 & 766.7 & $600-1120$ & 166.7 & \\
\hline \multirow[t]{2}{*}{ L15-4 } & 2005 & Male & 9 & 988.9 & $1000-1560$ & 44.7 & 17 Jun-23 Jun \\
\hline & & Female & 7 & 950.0 & $840-1090$ & 30.3 & \\
\hline \multirow[t]{2}{*}{ L15-9 } & 2005 & Male & 4 & 933.3 & $720-1230$ & 103.1 & $20 \mathrm{Jun}-3 \mathrm{Jul}$ \\
\hline & & Female & 6 & 975.0 & $860-1010$ & 87.6 & \\
\hline \multirow{2}{*}{ L15-25 } & 2004 & Male & 7 & 1185.7 & $1090-1510$ & 70.5 & 25 May-3 Jun \\
\hline & & Female & 20 & 905.0 & $680-1220$ & 39.0 & \\
\hline \multirow[t]{2}{*}{ M15-14 } & 2004 & Male & 11 & 972.7 & 610-1190 & 83.2 & $15 \mathrm{Jul}-21 \mathrm{Jul}$ \\
\hline & & Female & 8 & 837.5 & $630-970$ & 70.6 & \\
\hline \multirow[t]{2}{*}{ M15-14 } & 2005 & Male & 13 & 873.1 & $610-1050$ & 39.1 & 2 Aug-12 Aug \\
\hline & & Female & 4 & 750.0 & $600-900$ & 64.5 & \\
\hline \multirow{2}{*}{ M15-25 } & 2004 & Male & 9 & 966.7 & $590-1310$ & 91.3 & 29 Jun-8 Jul \\
\hline & & Female & 3 & 966.7 & $610-1290$ & 202.8 & \\
\hline \multirow[t]{2}{*}{ M15-25 } & 2005 & Male & 2 & 1075.0 & $950-1200$ & 125.0 & 25 Jul-1 Aug \\
\hline & & Female & 4 & 737.5 & $620-980$ & 102.8 & \\
\hline
\end{tabular}

were located within $19 \mathrm{~km}$ of each other and had similar topography and vegetative communities dominated by field bindweed (Convolvulis arvensis; Magle 2003, Magle and Crooks 2008). Within these colonies, between 20 and 100 medium-sized Tomahawk live traps (Tomahawk Live Trap, Tomahawk, WI, http://www.tomahawklivetrap.com) were set in a grid pattern approximately $10 \mathrm{~m}$ apart throughout the colony and baited with sweet feed (Severson and Plumb 1998). Trapping took place between May and August. Traps were set from 06:00 to 07:00 and left open throughout the morning, with the vast majority of captures occurring before noon (Hoogland 2003). All traps were monitored at all times by on-site research assistants. Trapped adult animals were weighed with a spring scale, and their sex was determined (Hoogland 1995). All animals were released at the site of capture following data collection, and individual prairie dogs were never weighed twice in 1 year. Juveniles were released without processing and were not evaluated by this study. Of the 7 colonies selected, I trapped and weighed prairie dogs on 4 colonies in 2004 and on the remaining 3 colonies in 2005. I also resampled 3 of the 2004 sampled colonies in 2005, for a total of 10 sampling units (colonies sampled by year). Population size for each colony was estimated using methods from Severson and Plumb (1998), and trapping continued until $20 \%$ of the estimated population was sampled.
A total of 217 prairie dogs were trapped and weighed, with an average of 21.7 prairie dogs per sampling unit (range 6-92; Table 1). No individual prairie dogs were weighed in both 2004 and 2005. All animal-handling protocols were authorized by Colorado State University's Animal Care and Use Committee (04085A-01).

Because body mass of prairie dogs fluctuates seasonally, average weight was summarized for male and female prairie dogs by month. I combined weight data from 2004 and 2005 to increase sample size for each month (Hoogland 2003). Because prairie dog weights may differ greatly by year (Hoogland 2003), I also summarized weights of prairie dogs for 2004 and 2005 separately. Using Mann-Whitney $U$-tests, I compared weights of males to those of females in each month. In separate analyses, I compared average weight for each month within sexes and pooled data within each year to test for differences in overall prairie dog body mass between 2004 and 2005 . I did not test differences in weights among colonies because colonies were sampled consecutively, so any differences would likely be due to seasonal trends. I compared the sex ratios of prairie dogs trapped overall, those trapped in 2004, and those trapped in 2005 to the expected ratio of $1: 1$ using $\chi^{2}$ tests.

In the pooled analysis combining 2004 and 2005, measured weights of female prairie dogs increased rapidly between May and July, with 


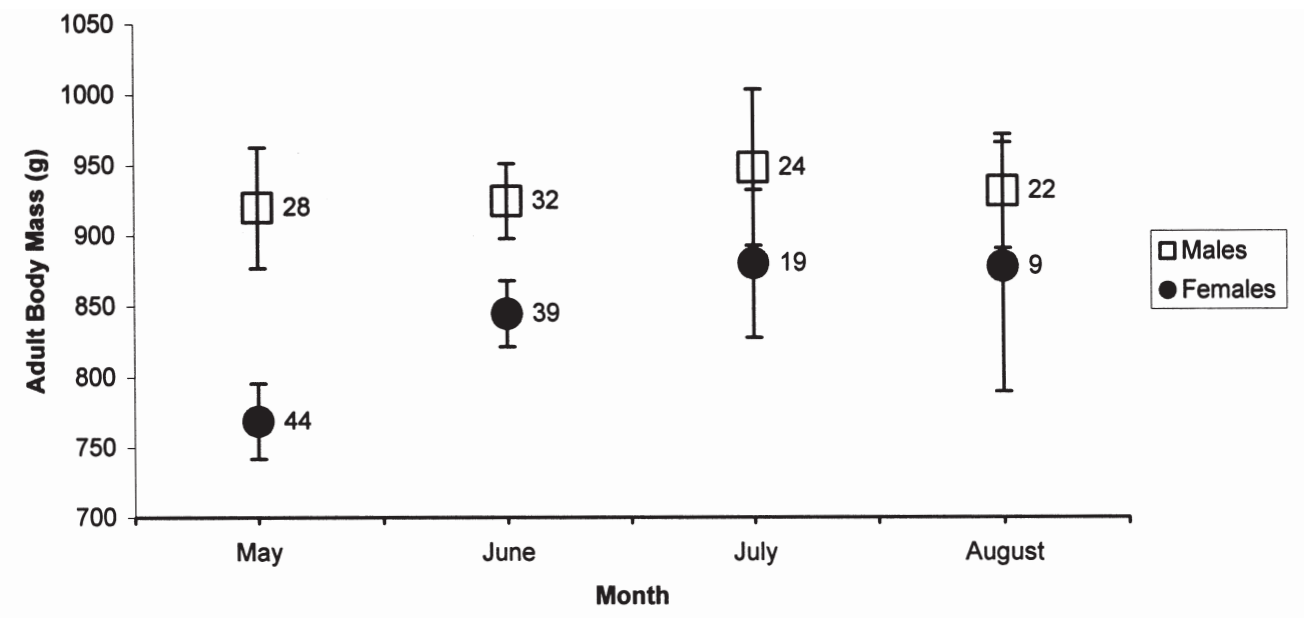

Fig. 1. Body mass of adult prairie dogs in urban habitat in Denver, Colorado, from 2004 and 2005, summarized by month. Differences between sexes were significant (Mann-Whitney $U$-test) for the months of May $(P=0.003)$ and June $(P=0.035)$, but not for July $(P=0.265)$ or August $(P=0.267)$. Symbols represent means, and bars represent 1 standard error.

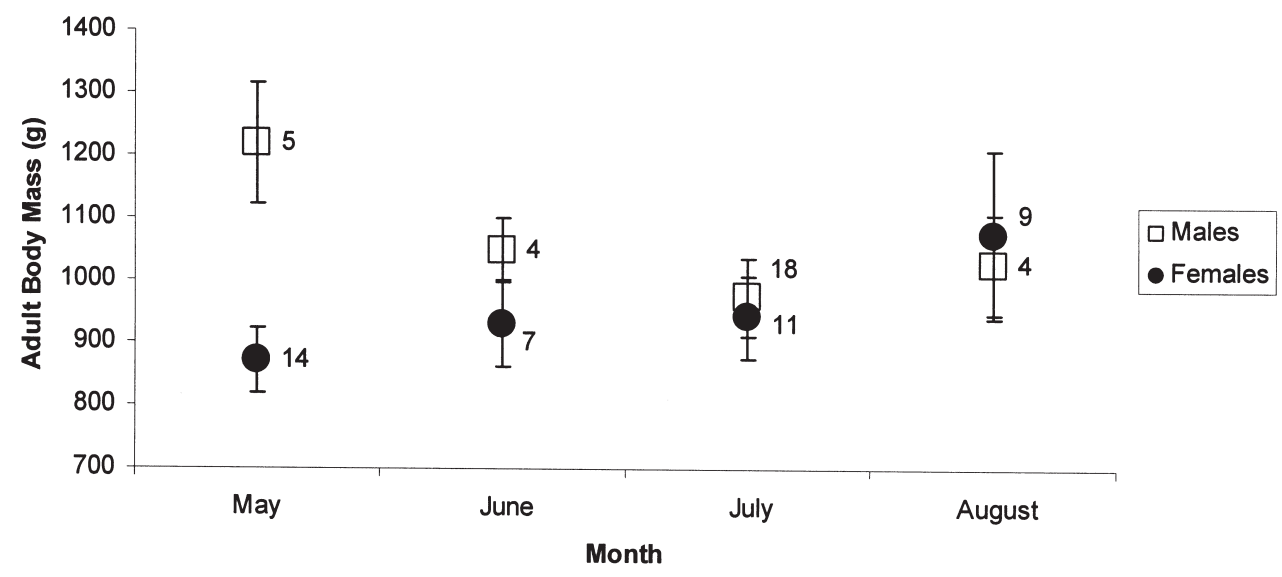

Fig. 2. Body mass of adult prairie dogs in urban habitat in Denver, Colorado, from 2004, summarized by month. Differences between sexes were significant (Mann-Whitney $U$-test) for the month of May $(P=0.001)$, but not for June $(P=$ $0.232)$, July $(P=0.480)$ or August $(P=0.930)$. Symbols represent means, and bars represent 1 standard error.

males generally fluctuating around a mean body weight of $930 \mathrm{~g}$, which was attained at least as early as May (Fig. 1). When evaluating only 2004 weights, however, I found that males were apparently heaviest in May and decreased in mass somewhat throughout the summer (Fig. 2). In 2005, males appeared relatively stable while females exhibited apparent declines in weight in July and August (Fig. 3). In both the combined analysis (2004 and 2005) and the separate 2005 analysis, males were significantly heavier than females in May and June, but not in July or August. In the analysis restricted to 2004, males were heavier than females only in May. Within sexes, females were heavier in June than in May in 2004, (MannWhitney $U$-test: $P=0.017$ ), and when years were combined $(P=0.011)$, but no other between-month differences were significant $(P$ $>0.05)$. In the analysis of body mass pooled by year, prairie dogs were significantly heavier in 2004 than in $2005(P<0.001)$. Sex ratio of trapped animals did not vary significantly from a 1:1 ratio in 2004 (37 males:36 females, 


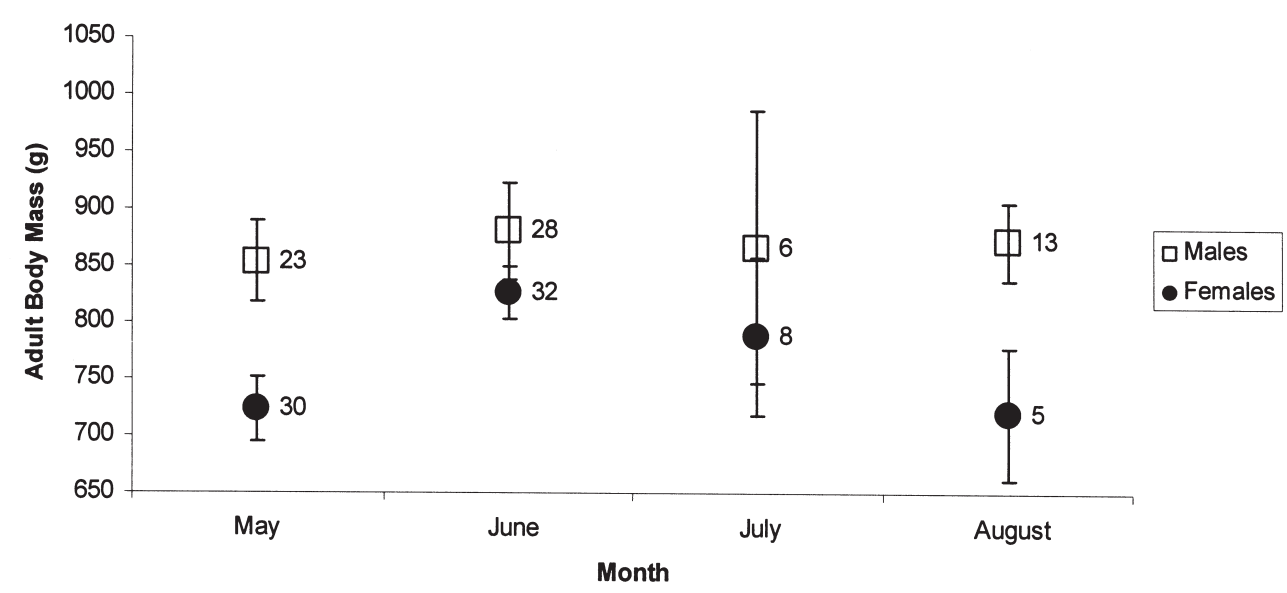

Fig. 3. Body mass of adult prairie dogs in urban habitat in Denver, Colorado, from 2005, summarized by month. Differences between sexes were significant (Mann-Whitney $U$-test) for the months of May $(P=0.003)$ and June $(P=$ $0.041)$, but not for July $(P=0.696)$ or August $(P=0.054)$. Symbols represent means, and bars represent 1 standard error.

$\left.\chi^{2}=0.007, P>0.1\right), 2005$ (69 males: 75 females, $\left.\chi^{2}=0.125, P>0.1\right)$, or overall $(106$ males: 111 females, $\left.\chi^{2}=0.058, P>0.1\right)$.

Although female prairie dogs in this study tended to gain weight during the summer, as in previous research (Hoogland 1995, 2003), the elevated body mass observed in males as early as May is unusual for this species (Hoogland 2003). This elevated body mass may be due to increased foraging by males in early spring, lack of competition for mates (i.e., less energetic expenditure to obtain matings), early recovery from competition for mates, or other factors. Although males were significantly heavier than females only in May and June, differences in July $(P=0.265)$ and August $(P$ $=0.267)$ would likely have been detected with increased sample size. It has been suggested that urban prairie dogs may have reduced body mass due to poor habitat quality and limited forage (Rayor 1985, Dawson 1991, Johnson and Collinge 2004), but prairie dogs in this study had body masses within or slightly above the normal range (approximately 700$900 \mathrm{~g})$ reported by Hoogland $(1995,2003)$ and Schwartz (2002). Even throughout the summer of 2004, when male body mass appeared to decline, monthly body mass values all exceeded 900 g. This study provides no evidence that urban prairie dog body mass is limited by reduced availability of forage, despite high densities of prairie dogs in these areas (Johnson and Collinge 2004, Magle et al. 2007), low levels of vegetative coverage, and high prevalence of exotic plant species (Magle 2003, Magle and Crooks 2008). The finding that prairie dog weights differed between 2004 and 2005 is consistent with findings that prairie dog body mass values frequently vary between years (Hoogland 2003).

When averaged through time, sexual dimorphism in this study was approximately $12 \%$; this is similar to values reported by Dawson (1991) and Hoogland $(1995,2003)$ for the summer months. Pizzimenti (1981) suggested that sexual dimorphism in prairie dogs is gradually increasing because of human disturbance, but this study provides no evidence to support this claim. Due to the longer lifespan of female prairie dogs, colonies typically have femaledominated sex ratios. Hoogland (1995, 2003) and Stockrahm (1979) found that disturbed (hunted) colonies had sex ratios more strongly skewed against males, but the sex ratios of my urban colonies did not differ significantly from a 1:1 ratio. However, my data do not represent censuses of colonies, and measured sex ratios may be biased if males or females are more easily trapped. Further research may be needed to clarify prairie dog sex ratios in disturbed or urban areas.

Animals in urban habitat sometimes exhibit novel behaviors (e.g., Sedgwick and Bartholow 2004) or modify existing behaviors (e.g., Adams et al. 1987, Magle et al. 2005). On 4 April 2003, I saw a prairie dog that had climbed 
approximately $1.5 \mathrm{~m}$ into a small shrub (Quercus spp.) and was eating leaves. To my knowledge, climbing behavior of this type has not been previously documented for prairie dogs. During the study I also frequently saw prairie dogs swimming across small drainage ditches ( $\leq 2 \mathrm{~m}$ wide) filled with water. It is possible that prairie dogs in urban environments are using novel foraging behaviors to maintain body mass despite low-quality forage.

This study provides basic information on body mass, sex ratios, and sexual dimorphism for prairie dogs in urban areas. These types of data have been relatively unknown for prairie dogs outside of certain key study areas (Hoogland 2003), and more research is required into how prairie dogs in urban systems interact with their environment in order to determine the specific long-term threats to the species. Although prairie dogs in urban areas face numerous threats, including human development, and may be susceptible to other hazards such as inbreeding, my study provides no evidence that limited forage is decreasing body mass or skewing sex ratios of urban prairie dogs. This is encouraging because urban prairie dog colonies serve an important role by increasing public awareness of prairie dogs and wildlife (Hoogland 2006). The fact that a species as important to prairie ecosystems as the prairie dog can persist in and colonize urban habitat refugia indicates the tremendous potential for conservation in such areas.

I thank C. Graves, M. Kaknes, E. Lee, M. Tauchen, and B. Williams for field assistance, and D. Stockrahm and 3 anonymous reviewers for comments on the manuscript. Funding was provided by the National Science Foundation, Colorado State University, the Denver Zoological Foundation, the Humane Society of the United States, the Rocky Mountain Goats Foundation, and a Sigma Xi grant-in-aid-ofresearch. I extend special thanks to K. Crooks for assistance with funding and guidance throughout the project.

\section{Literature Cited}

AdAms, R.A., B.J. LENGAS, AND M. Bekoff. 1987. Variations in avoidance responses to humans by blacktailed prairie dogs (Cynomys ludovicianus). Journal of Mammalogy 68:686-689.

Crooks, K.R., AND M. SANJAYAN, EDITORS. 2006. Connectivity conservation. Cambridge University Press, Cambridge, U.K.
Dawson, R.E. 1991. Comparison of body mass and demography between urban and rural populations of black-tailed prairie dogs (Cynomys ludovicianus). Master's thesis, University of Colorado, Boulder.

Forman, R.T.T., D. Sperling, J.A. Bissonette, A.P. Clevenger, C.D. Cutshall, V.H. Dale, L. Fahrig, et AL. 2003. Road ecology: science and solutions. Island Press, Washington, DC.

Hanski, I. 1998. Metapopulation dynamics. Nature 396:41-49.

HoOGLAND, J.L. 1995. The black-tailed prairie dog: social life of a burrowing mammal. University of Chicago Press, IL. 557 pp.

2003. Sexual dimorphism of prairie dogs. Journal of Mammalogy 84:1254-1266.

2006. Conservation of the black-tailed prairie dog: saving North America's western grasslands. Island Press, Washington, DC. 350 pp.

Johnson, W.C., And S.K. Collinge. 2004. Landscape effects on black-tailed prairie dog colonies. Biological Conservation 115:487-497.

Kaye, J.P., P.M. Groffman, N.B. Grimm, L.A. BaKer, and R.V. Pouyat. 2006. A distinct urban biogeochemistry? Trends in Ecology and Evolution 21:192-199.

Kotliar, N.B. 2000. Application of the new keystonespecies concept to prairie dogs: how well does it work? Conservation Biology 14:1715-1721.

Kotliar, N.B., B.W. BaKer, and A.D. Whicker. 1999. A critical review of assumptions about the prairie dog as a keystone species. Environmental Management 24:177-192.

Krebs, C.J., B.L. Keller, and R.H. Tamarin. 1969. Microtus population biology: demographic changes in fluctuating populations of $M$. ochrogaster and $M$. pennsylvanicus in southern Indiana. Ecology 50:587-607.

Lomolino, M.V., and G.A. Smith. 2001. Dynamic biogeography of prairie dog (Cynomys ludovicianus) towns near the edge of their range. Journal of Mammalogy 82:937-945.

2003. Prairie dog towns as islands: applications of island biogeography and landscape ecology for conserving nonvolant terrestrial vertebrates. Global Ecology and Biogeography 12:275-286.

MAGLE, S.B. 2003. Black-tailed prairie dog (Cynomys ludovicianus) response to human intrusion and urban development in the Colorado Front Range. Master’s thesis, University of Wisconsin, Madison. 2007. The persistence of prairie dogs in urban habitat islands in the Colorado Front Range. Doctoral dissertation, Colorado State University, Fort Collins.

Magle, S.B., AND K.R. CRooks. In preparation. Dispersal in urbanized black-tailed prairie dogs (Cynomys ludovicianus) is rare.

2008. Interactions between black-tailed prairie dogs (Cymomys ludovicianus) and vegetation in habitat fragmented by urbanization. Journal of Arid Environments 72:238-246.

Magle, S.B., B. McClintock, M. Antolin, D. Tripp, G. White, AND K.R. CrooKs. 2007. Mark-resight methodology for estimating population densities of prairie dogs. Journal of Wildlife Management 71:2067-2073.

Magle, S.B., J. Zhu, and K.R. Crooks. 2005. Behavioral responses to repeated human intrusion by blacktailed prairie dogs (Cynomys ludovicianus). Journal of Mammalogy 86:524-530. 
Miller, B., G. Ceballos, and R. Reading. 1994. The prairie dog and biotic diversity. Conservation Biology 8:677-681.

Miller, B., R. Reading, J. Hoogland, T. Clark, G. CebalLOS, R. List, S. Forrest, ET AL. 2000. The role of prairie dogs as a keystone species: response to Stapp. Conservation Biology 14:318-321.

Miller, B., C. Wemmer, D. Biggins, and R. Reading. 1990. A proposal to conserve black-footed ferrets and the prairie dog ecosystem. Environmental Management 14:763-769.

Pizzimenti, J.J. 1981. Increasing sexual dimorphism in prairie dogs: evidence for changes during the past century. Southwestern Naturalist 26:43-47.

RAYOR, L.S. 1985. Effects of habitat quality on growth, age of first reproduction, and dispersal in Gunnison's prairie dogs (Cynomys gunnisoni). Canadian Journal of Zoology 63:2835-2840.

SCHWARTZ, A.M. 2002. Surgical sterilization of the blacktailed prairie dog (Cynomys ludovicianus): a model for the effects of reproductive inhibition and hormonal reduction in the male. Master's thesis, Colorado State University, Fort Collins.

SedgWICK, J.A., AND J. Bartholow. 2004. Foxes on a hot tin roof. Western North American Naturalist 64:406408

Severson, K.E., and G.E. Plumb. 1998. Comparison of methods to estimate population densities of black- tailed prairie dogs. Wildlife Society Bulletin 26:859866.

Soulé, M.E., A.C. Alberts, and D.T. Bolger. 1992. The effects of habitat fragmentation on chaparral plants and vertebrates. Oikos 63:39-47.

Soulé, M.E., J.A. Estes, J. Berger, and C. Martinez DEL RIO. 2003. Ecological effectiveness: conservation goals for interactive species. Conservation Biology 17:1238-1250.

Soulé, M.E., J.A. Estes, B. Miller, and D.L. Honnold. 2005. Strongly interacting species: conservation policy, management, and ethics. BioScience 55:168176.

STAPP, P. 1998. A reevaluation of the role of prairie dogs in Great Plains grasslands. Conservation Biology 12: 1253-1259.

Stockrahm, D.M. 1979. Comparison of population structures of black-tailed prairie dog, Cynomys ludovicianus (Ord) towns in Southwestern North Dakota. Master's thesis, University of North Dakota, Grand Forks.

Vermeire, L.T., R.K. Heitschmidt, P.S. Johnson, B.F. SowELL. 2004. The prairie dog story: do we have it right? BioScience 54:689-695.

Received 1 March 2007 Accepted 28 August 2007 